\title{
Usefulness of the Measurement of Fractional Exhaled Nitric Oxide in Asthmatic Patients : Correlation with Pulmonary Function, Asthma Control and Health Status
}

\author{
Yoshiaki KitaGUCHI ${ }^{1)}$, Keisaku FujImoto ${ }^{2) *}$, Motoki ONO ${ }^{3)}$ \\ Yoshimichi Komatsu ${ }^{1)}$, Takayuki $\mathrm{HoNDA}^{4)}$ and Keishi $\mathrm{KUBO}^{1)}$ \\ 1) First Department of Internal Medicine, Shinshu University School of Medicine \\ 2) Departments of Biomedical Laboratory Sciences, Shinshu University School of Health Sciences \\ 3) Undergraduate, School of Medicine, Shinshu University School of Medicine \\ 4) Department of Laboratory Medicine, Shinshu University School of Medicine
}

Background and objective: This study was conducted to investigate whether or not FeNO correlates with lung function tests, the Asthma Control Test (ACT) for assessing asthma control or the Asthma Health Questionnaire (AHQ-33) for evaluating the health status in asthmatics.

Methods : FeNO was compared with the results of spirometry, ACT and AHQ-33 in 57 non-smoking patients with asthma and 17 healthy individuals without pulmonary diseases who had never smoked. Sixteen of 57 asthmatics treated with inhaled corticosteroid (ICS) underwent step-down therapy if they showed good/total control or step-up therapy if they showed poor control, and were evaluated by spirometry, ACT and AHQ33 prior to and more than one month after starting step-down or step-up therapy.

Results : FeNO in asthmatics was significantly higher than that in the control group. There were no significant correlations between $\mathrm{FeNO}$ and $\mathrm{FEV}_{1}$, ACT score or $\mathrm{AHQ}-33$ scores. However, there were significant correlations between the changes in FeNO and changes in $\mathrm{FEV}_{1}$, ACT score or AHQ-33 scores following stepdown or step-up therapy.

Conclusion : FeNO is a useful marker not only for the diagnosis of asthma but also for asthma control and determining the health status in an individual patient, although it is variable without any correlation with symptoms and lung function among asthmatics. Shinshu Med J 59 : 239-247, 2011

(Received for publication March 3, 2011 ; accepted in revised form May 10, 2011)

Key words : fractional exhaled nitric oxide, Asthma Control Test, Asthma Health Questionnaire

\section{Introduction}

Endogenous nitric oxide (NO) is an important signaling molecule and may play a role in the regulation of airway function ${ }^{12)}$. NO gas is produced by various cells within the lower respiratory tract, including inflammatory and epithelial cells, and is detectable in the exhaled air of normal human subjects ${ }^{3}$. Measurement of the fractional exhaled

\footnotetext{
* Corresponding author: Keisaku Fujimoto

Departments of Biomedical Laboratory Sciences, Shinshu University School of Health Sciences, 3-1-1 Asahi,

Matsumoto-city, Nagano-prefecture 390-8621, Japan
}

NO (FeNO) may be clinically useful for the detection and management of cytokine-mediated inflammatory lung disorders ${ }^{3)}$. The concentration of NO is increased in the exhaled air of asthmatics ${ }^{3 / 4}$. There is immunocytochemical evidence for inducible NO synthase (iNOS) expression in the airway epithelium of asthmatics ${ }^{5}$, suggesting that the increase in NO may be due to induction of iNOS by cytokines and other inflammatory mediators released in asthmatic airways. FeNO levels decrease following the treatment with the improvement of symptoms and airway obstruction in patients with acute asthma ${ }^{6}$. Therefore, the mea- 
surement of concentration of FeNO has been suggested to be a simple and noninvasive way of monitoring inflammation of the respiratory tract with a potential role in the diagnosis of disease ${ }^{7 / 8)}$.

However, FeNO is affected by the treatment for asthma, especially inhaled corticosteroid (ICS) and the type of airway inflammation, eosinophilic or neutrophilic airway inflammation. Some investigators doubt the usefulness of FeNO as a marker of asthma control. This study cross-sectionally examined whether FeNO was correlated with asthma control or airflow limitation among asthma patients who had received daily treatments for asthma including ICS and further examined the relationship between the changes in FeNO and asthma symptoms or airflow limitation in individual asthma patient when the treatment underwent either a step-down or step-up longitudinally.

\section{Methods}

\section{A Subjects}

Fifty-seven non-smoking asthmatics were recruited from the outpatient clinics of Shinshu University Hospital from April 2009 to September 2009. Asthma was diagnosed based on the clinical history and symptoms including reversible airflow limitation in accordance with the Global Initiative for Asthma (GINA) guidelines ${ }^{9}$. Thirteen of the 57 asthmatic patients had never received any steroid therapy, 38 patients were treated with ICS of 400 ug/day fluticasone propionate, and 6 patients with maintenance $2.5-20 \mathrm{mg} /$ day oral prednisolone $(7.9 \pm$ $2.6 \mathrm{mg} /$ day) added to ICS therapy. In addition, 40 patients were treated with leukotriene receptor antagonist (LTRA), 13 with long-acting $\beta_{2}$-agonists (LABA), and 22 with oral theophylline.

Seventeen non-smoking controls took part in the study. None of them had histories of respiratory or cardiovascular diseases or received any long-term medications.

This study was approved by the Human Ethics Committee of Shinshu University School of Medicine.

\section{B Study design}

FeNO was evaluated in comparison to the results of the Asthma Control Test (ACT) for assessing asthma control ${ }^{10) 11)}$ and the Asthma Health Questionnaire (AHQ-33), which is a health-related quality of life questionnaire for asthmatics ${ }^{12) 13}$. All subjects completed a questionnaire regarding their prior respiratory diagnosis, smoking history and current medication use, the ACT and the AHQ-33, and then underwent FeNO measurement and spirometry. These evaluations were done between 9 am and 11 am.

Thirteen of 38 asthmatics on ICS therapy whose asthma control varied from good to total control with an ACT score of 21 25 underwent step-down of their therapy, reducing either LTRA, LABA or theophylline, and three asthmatics whose asthma control was poor with an ACT score below 20 underwent step-up of their therapy. Spirometry, the measurement of FeNO, the evaluation of ACT and AHQ-33 questionnaires were examined before and 1 to 6 months after either the step-down or step-up.

\section{Pulmonary function tests}

Spirometry was performed using a pulmonary function testing system (Chestac-55V ; Chest Co. Ltd., Tokyo, Japan). The pulmonary function tests were performed by two special technicians according to the ATS criterion. Two or three tests were repeated to guarantee repeatability.

\section{Fractional exhaled Nitric Oxide measurement}

FeNO measurement was performed with a previously described technique ${ }^{14)}$. FeNO levels were evaluated using a personal device (NIOX MINO; Aerocrine AB ; Smidesvägen, Sweden) for measuring FeNO levels with identical mouth flow rate and pressure settings in each subject. The sensor on the device was changed periodically, in line with the manufacturer's guidance. The working of the device is based on electrochemical analysis, which is in line with published procedures for FeNO measurement. The method has been validated by chemiluminescence technology, with an accuracy of \pm 5 parts per billion (ppb) in comparison to the personal device (NIOX MINO; Aerocrine AB; Smidesvägen, Sweden). Data from the analyzer vs. the portable 
device (NIOX; Aerocrine AB; Smidesvägen, Sweden) showed a mean disagreement of $0.5 \mathrm{ppb}$ (SD, $3.8 \mathrm{ppb}$ ), with high linearity and accuracy in comparison to reference gases ${ }^{15)}$. Two successive recordings were made at 2 -min intervals, and the average of two readings was recorded. All measurements were made by a single observer who had no knowledge of the treatment of individual patients.

\section{E Asthma Control Test (ACT) survey}

The ACT survey is a patient-completed questionnaire with 5 items assessing asthma symptoms (daytime and nocturnal), use of rescue medications, and the effect of asthma on daily functioning. Each item includes 5 response options corresponding to a $5^{-}$ point Likert-type rating scale. In scoring the ACT score, responses for each of the 5 items are summed to yield a score ranging from 5 (poor control of asthma) to 25 (complete control of asthma). The details of the development of the ACT have been reported elsewhere ${ }^{10)}$.

\section{F Asthma Health Questionnaire-33-Japan (AHQ-33)}

The AHQ-33, which is a disease-specific healthrelated quality of life questionnaire that is widely used in Japan, was employed to assess health status. AHQ-33 was developed based on international questionnaires such as the Asthma Quality of Life Questionnaire (AQLQ) by translating from the English language, while taking into account both Japanese customs and culture. A higher score on the AHQ-33 reflects poorer health status with respect to these 33 items. Muraki et al. ${ }^{12)}$ showed that the AHQ-33 was more sensitive for severity than the Medical Outcomes Study Short-Form 36-Item Health Survey (SF-36) which was widely used as a generic health-related quality of life questionnaire, and that a logistic regression analysis revealed that asthmatic symptoms, factors which worsened symptoms, emotion, daily activity, and social activity subscale scores, as well as a high total 32 item score, on the $\mathrm{AHQ}-33$ were associated with an increased risk of moderate to severe asthma. The details of the development of the AHQ-33 have been reported elsewhere ${ }^{13)}$.

\section{G Statistical Analysis}

The values shown in the text and tables are the means \pm SEM. The variables in the two groups were compared with the use of nonparametric Mann-Whitney's U tests. Simple correlations between variables were examined by calculating Pearson's product correlation coefficient. All statistical analyses were performed with the use of a Windows-compatible software package (Stat Flex ver. 5.0, Artech Ltd., Osaka, Japan). A P-value of less than 0.05 was considered to be significant in all statistical analyses.

\section{Results}

FeNO was significantly higher in asthmatics than in control subjects (Table 1). There was no significant correlation between FeNO and percent predicted $\mathrm{FEV}_{1}$ in asthmatics (Fig. 1). There was no significant correlation between $\mathrm{FeNO}$ and $\mathrm{FEV}_{1} /$ FVC $(r=-0.14)$ and no significant difference in FeNO between asthmatics with and without airway obstruction $(62.7 \pm 8.3$ vs. $46.6 \pm 6.0 \mathrm{ppb})$. There was no significant correlation between FeNO and ACT score or $\mathrm{AHQ}^{-33}$ total score (Fig. 2) as well as subscale scores of $\mathrm{AHQ}^{-33}$. On the other hand, there was a significant correlation between ACT score and $\mathrm{AHQ}^{-33}$ total score $(\mathrm{r}=-0.67, \mathrm{p}<0.01)$.

The asthmatics were classified into the three subgroups in accordance with the treatment with no

Table 1 Comparison of the clinical characteristics, pulmonay function tests and the fractional exhaled nitric oxide (FeNO) of control subjects and asthmatics

\begin{tabular}{l|c|c}
\hline & Control & Asthma \\
\hline \hline Number of patients, $\mathrm{n}$ & 17 & 57 \\
\hline Age, yrs old & $53.1 \pm 4.1$ & $54.4 \pm 2.1$ \\
\hline Sex, female/male, n/n & $4 / 13$ & $26 / 31$ \\
\hline$\% \mathrm{VC}, \%$ & $110.8 \pm 5.4$ & $95.4 \pm 4.3$ \\
\hline$\% \mathrm{FEV}_{1}, \%$ & $108.4 \pm 4.7$ & $79.6 \pm 4.3^{* *}$ \\
\hline $\mathrm{FEV}_{1} / \mathrm{FVC}, \%$ & $82.2 \pm 1.6$ & $70.0 \pm 2.1^{* *}$ \\
\hline $\mathrm{FeNO}, \mathrm{ppb}$ & $23.7 \pm 2.4$ & $53.9 \pm 6.9^{* *}$ \\
\hline
\end{tabular}

Values are the mean \pm SEM. ${ }^{* *} \mathrm{p}<0.01$ vs. Control 


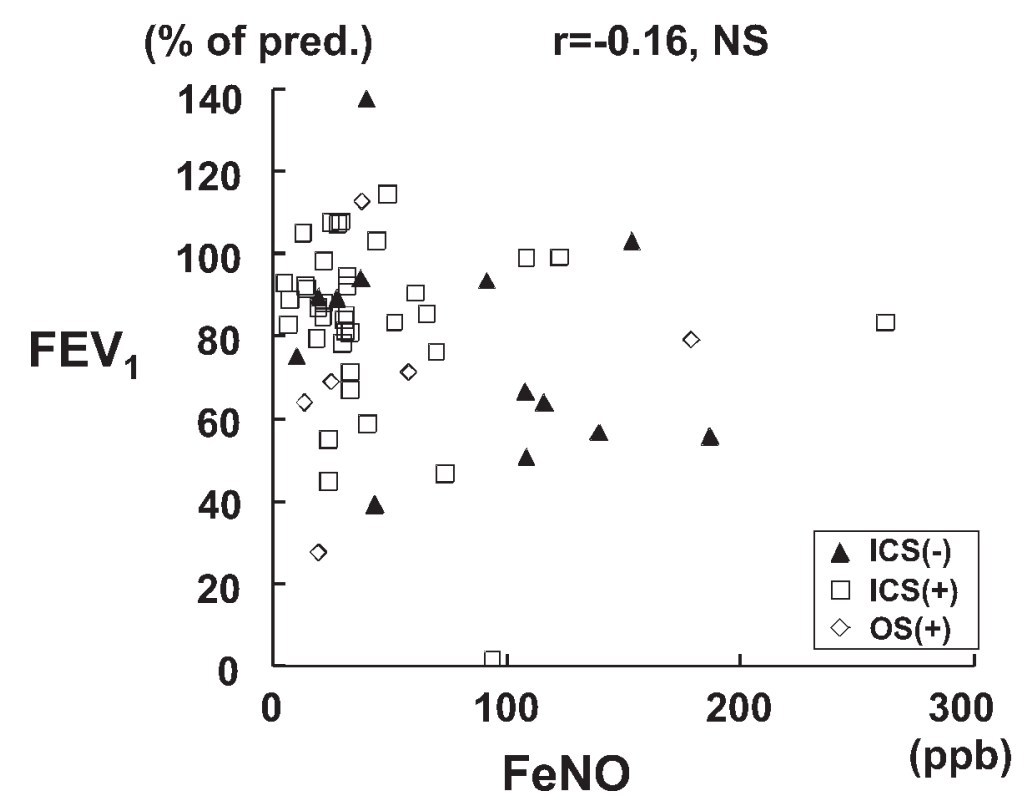

Fig. 1 Correlation between the fractional exhaled nitric oxide (FeNO) and percent predicted $\mathrm{FEV}_{1}$ in asthmatics $(\mathrm{n}=57)$
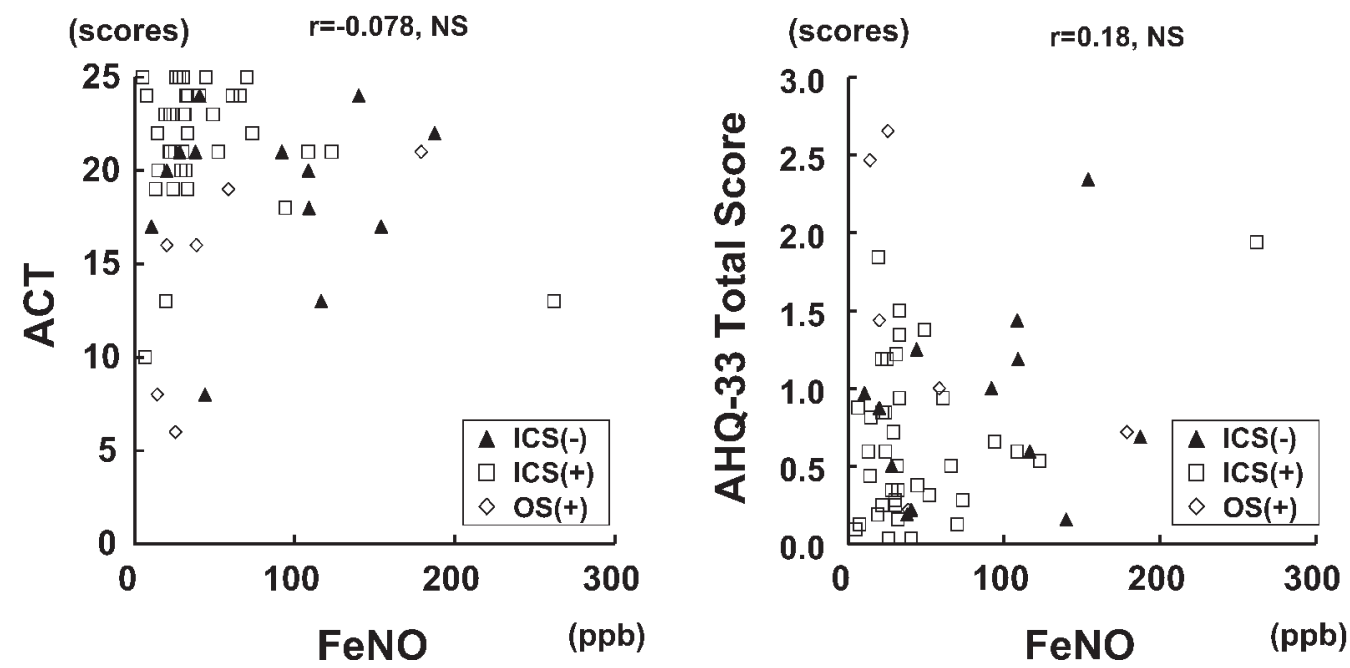

Fig. 2 Correlation between the fractional exhaled nitric oxide (FeNO) and the Asthma Control Test (ACT) or the Asthma Health Questionnare-33 (AHQ-33) in asthmatic patients $(n=57)$

corticosteroids (steroid-naive group), ICS (ICS group), and oral corticosteroid + ICS (OS group). FeNO was significantly higher in steroid-naïve asthmatics $(83.7 \pm 15.9 \mathrm{ppb})$ and asthmatics treated with ICS $(43.4 \pm 7.3 \mathrm{ppb})$ than in control subjects $(23.7 \pm 2.4 \mathrm{ppb})$, and the FeNO in steroid-naïve asthmatics was significantly higher than that in asthmatics in the ICS group (Fig. 3). The FeNO in asthmatics treated with oral corticosteroid (55.9 \pm $25.5 \mathrm{ppb})$ tended to be lower than in steroid-naïve asthmatics and higher than in control subjects, but there were no significant differences among these groups. There were no significant correlations between FeNO and the percent predicted $\mathrm{FEV}_{1}$ $(\mathrm{r}=-0.33)$, ACT score $(\mathrm{r}=0.12)$ or $\mathrm{AHQ}-33$ total score $(r=0.28)$ as well as the subscale scores of AHQ-33 in steroid-naïve asthmatics.

Changes in FeNO were compared with changes in pulmonary function tests, ACT and AHQ-33 scores of 16 asthmatics who underwent step-down or stepup of their therapy (Table 2). The concentrations of FeNO were increased in 10 of the 13 asthmatics that 
Usefulness of the measurement of FeNO in asthmatic patients

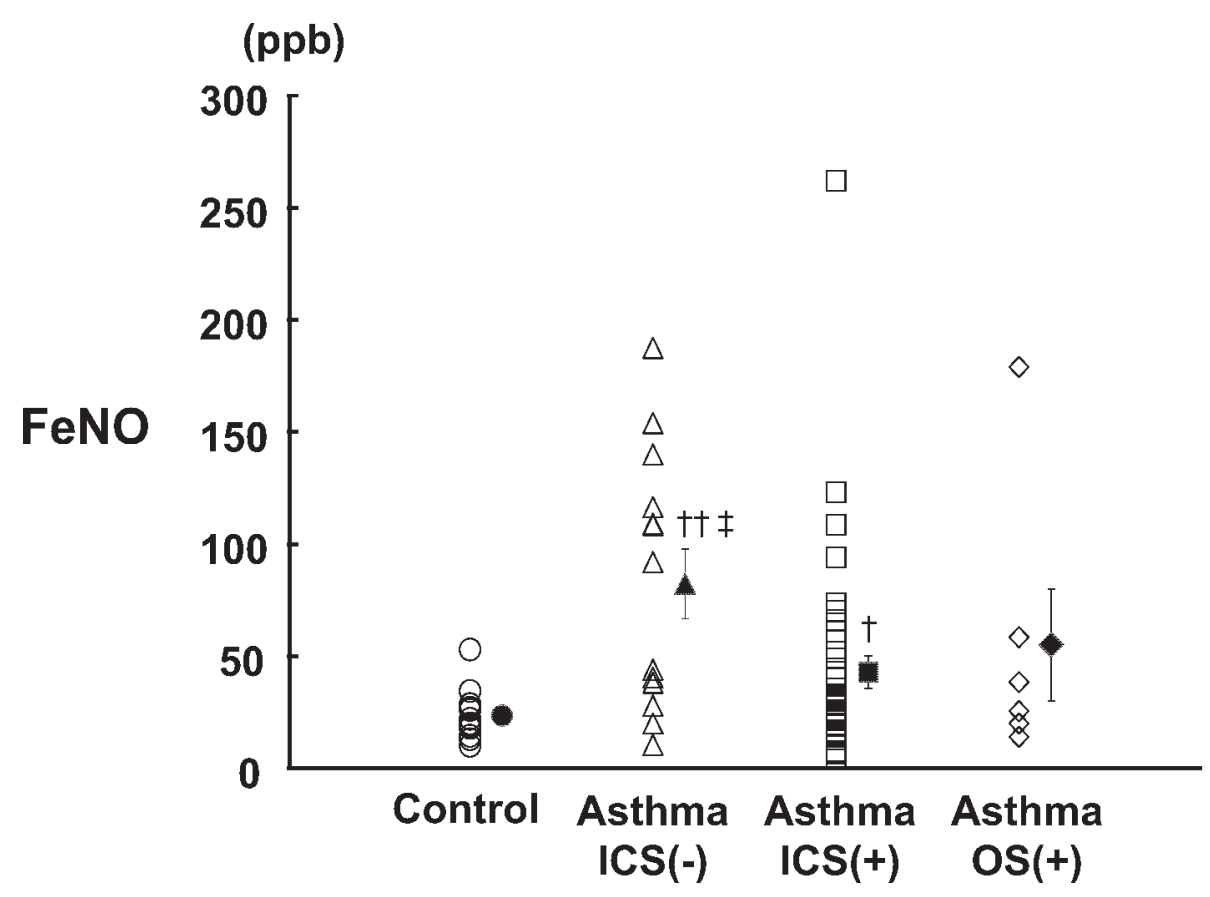

Fig. 3 The fractional exhaled nitric oxide $(\mathrm{FeNO})$ in control subjects $(\bigcirc, \mathrm{n}=17)$, steroid-naive asthmatics $(\triangle, \mathrm{n}=13)$, asthmatics treated with inhaled corticosteroid $(\square, \mathrm{n}=38)$ and asthmatics treated with maintenance oral steroids $(\diamond, \mathrm{n}=6)$

- (Control), $\boldsymbol{\Delta}$ (Asthma ICS $(-)$ ), $\boldsymbol{\square}$ (Asthma ICS $(+))$ and $\bullet$ (Asthma OS $(+))$; mean \pm SEM. ${ }^{\dagger} \mathrm{p}<0.05$ and ${ }^{\dagger \dagger} \mathrm{p}<0.01$ vs. Control, ${ }^{\ddagger} \mathrm{p}<0.05$ vs. Asthma ICS $(+)$

underwent step-down, and all three asthmatics that underwent step-up showed decreases in their FeNO. There was a significant correlation between the changes in FeNO and the changes in $\mathrm{FEV}_{1}(\mathrm{r}=-0$. $66, \mathrm{p}<0.01)$, ACT score $(\mathrm{r}=-0.56)$ or AHQ-33 total scores $(r=0.77, p<0.01)$ as well as the 4 subscale scores (Fig. 4).

\section{Discussion}

FeNO was significantly higher in asthmatics. There were no significant correlations between $\mathrm{FeNO}$ and the percent predicted $\mathrm{FEV}_{1}, \mathrm{ACT}$ score for assessing asthma control or any of the AHQ-33 subscale scores for evaluating health status. There was no significant difference in FeNO between asthmatics with and without airway obstruction. FeNO was significantly higher in steroid-naïve asthmatics than in asthmatics on ICS therapy. There were no significant correlations even between FeNO and percent predicted $\mathrm{FEV}_{1}$, ACT score or any of the AHQ-33 subscale scores in steroid-naïve asthmatics. However, there were significant correla- tions between changes in FeNO and changes in $\mathrm{FEV}_{1}$, ACT score or AHQ-33 total scores as well as 4 subscale scores in asthmatics who underwent step- down or step-up of their therapy without any changes of the ICS dose.

FeNO increases in association with eosinophilic airway inflammation measured in BAL, airway tissue and induced sputum in asthmatics and decreases following treatment with ICS $^{16}$. FeNO is a reliable surrogate marker of eosinophilic airway inflammation ${ }^{34) 17}$ ). Daily monitoring of FeNO by the portable device (NIOX MINO; Aerocrine AB; Smidesvägen, Sweden) is a feasible method to monitor airway inflammation in asthmatics ${ }^{18) 19}$. However, FeNO is directly affected by the administration of ICS even at lower doses and shows lower levels in symptomatic asthmatics treated with ICS than in steroid-naïve asthmatics since corticosteroids inhibit iNOS in the airway ${ }^{16) 20}$. A cross-sectional observation in this study showed there was no significant correlation between FeNO and percent predicted $\mathrm{FEV}_{1}$, ACT score or any of the AHQ-33 
Kitaguchi $\cdot$ Fujimoto Ono et al.

Table 2 Changes in FeNO and $\mathrm{FEV}_{1}$ in thirteen asthmatics (No. 1-13) that underwent step-down and three asthmatics (No. 14-16) that underwent step-up among 38 asthmatics on ICS therapy

\begin{tabular}{|c|c|c|c|c|c|c|c|}
\hline $\begin{array}{l}\text { Patient } \\
\text { number }\end{array}$ & $\begin{array}{l}\text { Step-down or step-up } \\
\text { Before }\end{array}$ & After & $\begin{array}{l}\text { Observation } \\
\text { period (days) }\end{array}$ & $\begin{array}{c}\Delta \mathrm{FeNO} \\
(\mathrm{ppb})\end{array}$ & $\begin{array}{l}\Delta \mathrm{FEV}_{1} \\
(\mathrm{ml})\end{array}$ & $\begin{array}{l}\Delta \mathrm{ACT} \\
\text { (scores) }\end{array}$ & $\begin{array}{c}\Delta \mathrm{AHQ}^{-33} \\
\text { (scores) }\end{array}$ \\
\hline 1 & $\mathrm{ICS}+\mathrm{LABA}+\mathrm{LT}+\mathrm{Th}$ & $\mathrm{ICS}+\mathrm{LABA}+\mathrm{Th}$ & 120 & +37.5 & +20 & 0 & +0.41 \\
\hline 2 & $\mathrm{ICS}+\mathrm{LABA}+\mathrm{LT}$ & $\mathrm{ICS}+\mathrm{LABA}$ & 106 & +22.0 & +60 & 0 & -0.19 \\
\hline 3 & $\mathrm{ICS}+\mathrm{LABA}+\mathrm{LT}+\mathrm{Th}$ & $\mathrm{ICS}+\mathrm{LABA}+\mathrm{LT}$ & 133 & +20.5 & +280 & -1 & +0.19 \\
\hline 4 & $\mathrm{ICS}+\mathrm{LABA}+\mathrm{LT}+\mathrm{Th}$ & $\mathrm{ICS}+\mathrm{LABA}+\mathrm{Th}$ & 118 & +17.5 & +20 & +4 & -0.47 \\
\hline 5 & $\mathrm{ICS}+\mathrm{LABA}+\mathrm{LT}+\mathrm{Th}$ & $\mathrm{ICS}+\mathrm{LABA}+\mathrm{Th}$ & 46 & +19.5 & -120 & -4 & +0.19 \\
\hline 6 & $\mathrm{ICS}+\mathrm{LABA}+\mathrm{LT}+\mathrm{Th}$ & $\mathrm{ICS}+\mathrm{LABA}+\mathrm{Th}$ & 121 & +21.5 & -100 & 0 & 0.00 \\
\hline 7 & $\mathrm{ICS}+\mathrm{LABA}+\mathrm{LT}$ & $\mathrm{ICS}+\mathrm{LT}$ & 182 & +57.5 & -380 & -4 & +0.47 \\
\hline 8 & $\mathrm{ICS}+\mathrm{LABA}+\mathrm{LT}$ & $\mathrm{ICS}+\mathrm{LT}$ & 170 & 0.0 & +50 & +1 & -0.09 \\
\hline 9 & $\mathrm{ICS}+\mathrm{LABA}+\mathrm{LT}$ & $\mathrm{ICS}+\mathrm{LT}$ & 85 & +5.5 & 0 & +1 & -0.16 \\
\hline 10 & $\mathrm{ICS}+\mathrm{LABA}+\mathrm{LT}$ & $\mathrm{ICS}+\mathrm{LT}$ & 85 & +8.0 & -90 & -3 & 0.00 \\
\hline 11 & $\mathrm{ICS}+\mathrm{LABA}+\mathrm{LT}+\mathrm{Th}$ & $\mathrm{ICS}+\mathrm{LT}+\mathrm{Th}$ & 112 & -6.5 & +150 & 0 & -0.13 \\
\hline 12 & $\mathrm{ICS}+\mathrm{LABA}+\mathrm{LT}+\mathrm{Th}$ & $\mathrm{ICS}+\mathrm{LT}+\mathrm{Th}$ & 86 & +78.0 & +20 & -3 & -0.13 \\
\hline 13 & $\mathrm{ICS}+\mathrm{LABA}+\mathrm{LT}$ & $\mathrm{ICS}+\mathrm{LABA}$ & 166 & -2.0 & -120 & -1 & -0.28 \\
\hline 14 & $\mathrm{ICS}+\mathrm{LABA}$ & $\mathrm{ICS}+\mathrm{LABA}+\mathrm{LT}$ & 30 & -35.5 & +440 & +18 & -1.72 \\
\hline 15 & $\mathrm{ICS}+\mathrm{LT}$ & $\mathrm{ICS}+\mathrm{LT}+\mathrm{LABA}+\mathrm{Th}$ & 127 & -47.5 & +30 & +2 & -0.53 \\
\hline 16 & ICS & $\mathrm{ICS}+\mathrm{LABA}+\mathrm{LT}+\mathrm{Th}$ & 136 & -210.0 & +470 & +8 & -1.63 \\
\hline \multicolumn{3}{|c|}{$\begin{array}{l}\text { Mean } \\
\pm \text { SEM }\end{array}$} & $\begin{array}{l}113.9 \\
\pm 10.4\end{array}$ & $\begin{array}{l}-0.9 \\
\pm 15.9\end{array}$ & $\begin{array}{c}45.6 \\
\pm 53.3\end{array}$ & $\begin{array}{c}1.1 \\
\pm 1.4\end{array}$ & $\begin{array}{l}-0.25 \\
\pm 0.15\end{array}$ \\
\hline
\end{tabular}

ICS ; inhaled corticosteroid (fluticasone propionate $400 \mathrm{ug} /$ day), LABA ; long-acting $\beta_{2}$-agonist (salmeterol xinafoate $100 \mathrm{ug} /$ day), LTRA : leukotriene receptor antagonist (montelukast sodium $10 \mathrm{mg} /$ day or pranlukast hydrate $450 \mathrm{mg} /$ day), Th; theophylline (400 $\mathrm{mg} /$ day)

$\Delta \mathrm{FeNO}, \Delta \mathrm{FEV}_{1}, \Delta \mathrm{ACT}$ and $\triangle \mathrm{AHQ}-33$; changes in $\mathrm{FeNO}, \mathrm{FEV}_{1}, \mathrm{ACT}$ and $\mathrm{AHQ}^{-3} 3$ between the days before and after step-down or step-up

subscale scores in all asthmatics and even in steroid- naïve asthmatic patients, respectively, suggesting that FeNO is variable without any correlation with symptoms and lung function among asthmatics.

There is the possibility that subject-related factors influenced these results. FeNO may be influenced by several subject-related factors other than eosinophilic inflammation such as age, gender and medications including oral/inhaled corticosteroids, beta-agonists and LTRA ${ }^{17)}$. FeNO may not accurately reflect airway inflammation in ICS-treated patients ${ }^{2122)}$. The other reason may be due to heterogeneity of airway inflammation in asthmatics. Eosinophilic airway inflammation is charac- teristic in asthma. However, some persistent asthmatics also demonstrate neutrophilic airway inflammation without eosinophilic airway inflammation ${ }^{23)}$, and some patients show increases in not only eosinophilic airway inflammation but also neutrophilic airway inflammation during exacerbation of asthma ${ }^{24)}$. According to previous crosssectional studies, FeNO is correlated with percent predicted $\mathrm{FEV}_{1}$ in asthmatics ${ }^{25}$. On the other hand, Stirling et al. reported that FeNO was not correlated with percent predicted $\mathrm{FEV}_{1}{ }^{26}$. Most of the patients in this study had a long history of asthma (more than 5 years), and some patients showed fixed airflow obstruction. The airway remodeling may have affected the results in this study. 

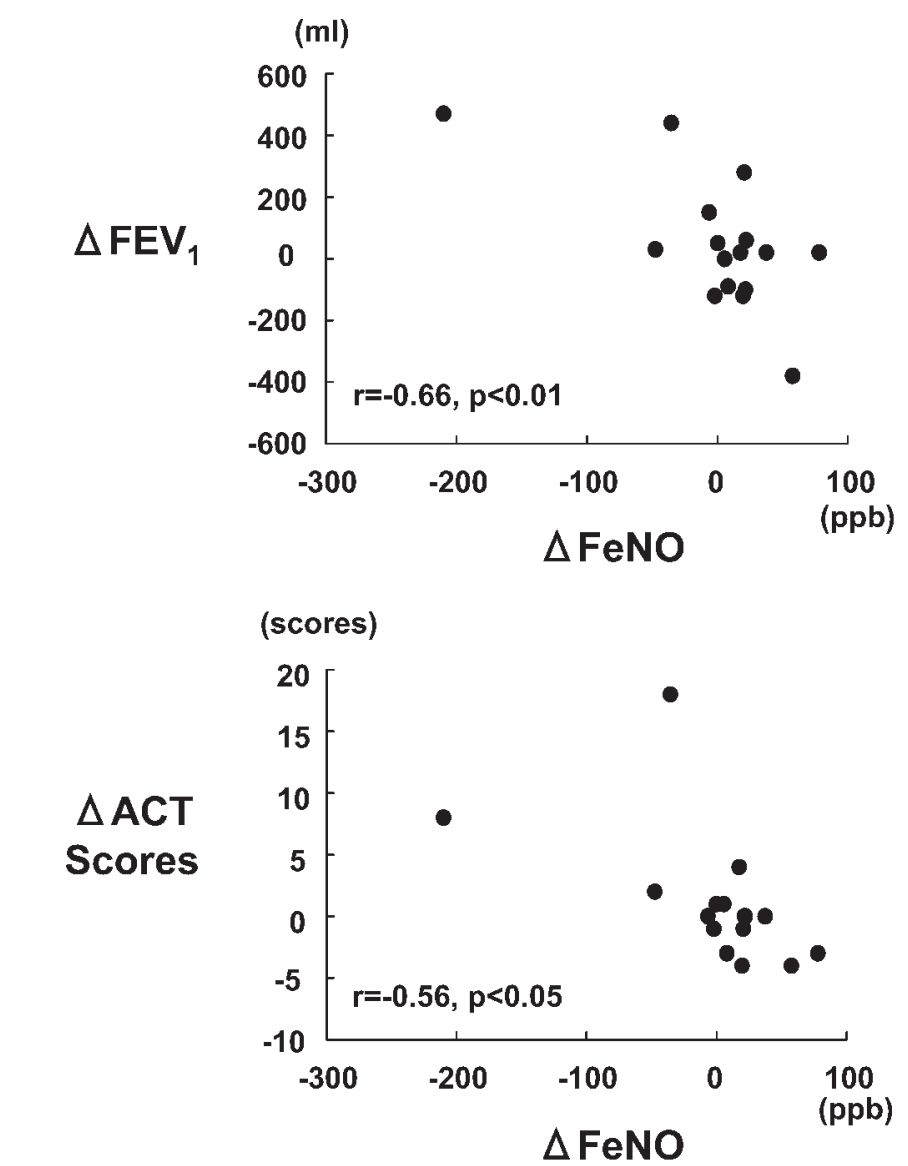

Fig. 4 Correlation between the changes in the fractional exhaled nitric oxide (FeNO) and changes in $\mathrm{FEV}_{1}$, changes in the Asthma Control Test (ACT) score or changes in the Asthma Health Questionnar$\mathrm{e}^{-33}$ (AHQ-33) in thirteen asthmatics that underwent step-down and three asthmatics that underwent step-up among 38 asthmatics on ICS therapy $(n=16)$

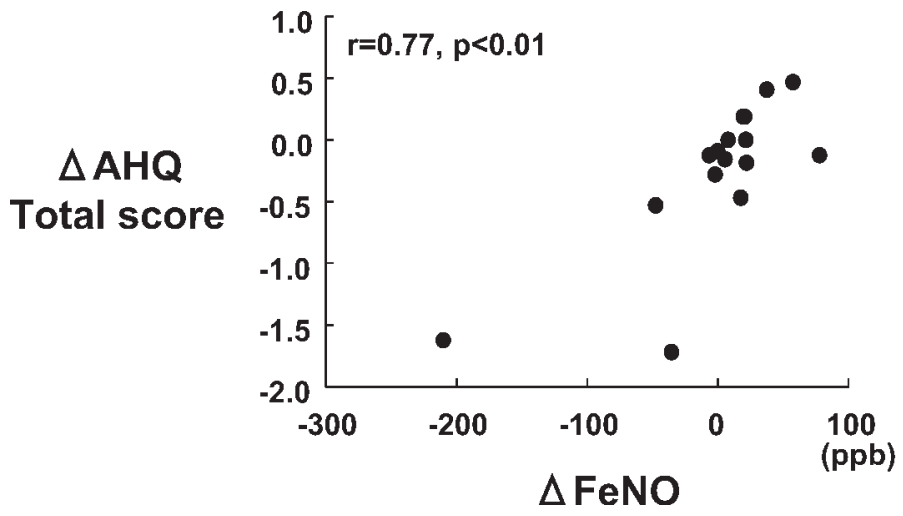

The novel finding in this study is that there was a significant correlation between changes in FeNO and changes in percent predicted $\mathrm{FEV}_{1}$, ACT score or AHQ-33 total scores as well as 4 subscale scores in asthmatics who received step-down or step-up therapy with LABA, LTRA or theophylline without any changes of ICS dose. This finding suggests that FeNO is a useful marker for asthma control and determining health status during the course of treatment. In the previous studies, Jatakanon et al. repor- ted that monitoring FeNO and sputum eosinophils may be useful in the assessment of airway inflammatory changes following ICS therapy in asthmatics $^{20)}$. Massaro et al. reported that FeNO levels were decreased accompanying improvement in airway obstruction in patients with acute asthma during their course of treatment with corticosteroids $^{6)}$, suggesting that FeNO may prove useful as an index of asthma severity and treatment efficacy for an individual patient. The current study found that 
FeNO was increased in parallel with the exacerbated symptoms and deterioration of pulmonary function following step-down by reducing either LABA, LTRA or theophylline while continuing ICS. These findings may suggest that FeNO is useful marker for asthma control under treatment with ICS.

In conclusion, FeNO is considered to be a useful marker not only for the diagnosis of asthma, but also for asthma control and determining the health status in individual patients, although it is variable without any correlation with the symptoms and lung function among asthmatics.

\section{Acknowledgements}

We thank Dr. Hiroko Arioka (Department of Respiratory Medicine, International Medical Center of Japan) for providing the Asthma Health Questionnaire-33-Japan.

\section{References}

1) Barnes PJ, Belvisi MG : Nitric oxide and lung disease. Thorax 48 : 1034-1043, 1993

2) Gaston B, Drazen JM, Loscalzo J, Stamler JS: The biology of nitrogen oxides in the airways. Am J Respir Crit Care Med 149 : 538-551, 1994

3) Kharitonov SA, Yates D, Robbins RA, Logan-Sinclair R, Shinebourne EA, Barnes PJ : Increased nitric oxide in exhaled air of asthmatic patients. Lancet 343 : 133-135, 1994

4) Alving K, Weitzberg E, Lundberg JM : Increased amount of nitric oxide in exhaled air of asthmatics. Eur Respir J $6: 1368-1370,1993$

5) Hamid Q, Springall DR, Riveros-Moreno V, Chanez P, Howarth P, Redington A, Bousquet J, Godard P, Holgate S, Polak JM : Induction of nitric oxide synthase in asthma. Lancet 342 : 1510-1513, 1993

6) Massaro AF, Gaston B, Kita D, Fanta C, Stamler JS, Drazen JM : Expired nitric oxide levels during treatment of acute asthma. Am J Respir Crit Care Med 152: 800-803, 1995

7) Kharitonov S, Alving K, Barnes PJ : Exhaled and nasal nitric oxide measurements: recommendations. The European Respiratory Society Task Force. Eur Respir J 10 : 1683-1693, 1997

8) Barnes PJ, Kharitonov SA : Exhaled nitric oxide : a new lung function test. Thorax 51 : 233-237, 1996

9) Global Initiative for Asthma (GINA). Global strategy for Asthma Management and Prevention. Updated 2008. http : //www.ginasthma.com/.

10) Nathan RA, Sorkness CA, Kosinski M, Schatz M, Li JT, Marcus P, Murray JJ, Pendergraft TB : Development of the asthma control test : a survey for assessing asthma control. J Allergy Clin Immunol 113 : 59-65, 2004

11) Schatz M, Sorkness CA, Li JT, Marcus P, Murray JJ, Nathan RA, Kosinski M, Pendergraft TB, Jhingran P : Asthma Control Test: reliability, validity, and responsiveness in patients not previously followed by asthma specialists. J Allergy Clin Immunol 117 : 549-556, 2006

12) Muraki M, Ichihashi H, Haraguchi R, Iwanaga T, Kubo H, Tohda Y: Comparison of the Asthma Health Questionnaire-33-Japan and the short-form 36-item health survey for measuring quality of life in Japanese patients with asthma. Allergol Int $57: 339-346,2008$

13) Arioka H, Kobayashi K, Kudo K, Kabe J : Validation study of a disease-specific module, the Asthma Health Questionnaire (AHQ) using Japanese adult asthmatic patients. Allergol Int 54:473-482, 2005

14) Bodini A, Peroni D, Loiacono A, Costella S, Pigozzi R, Baraldi E, Boner AL, Piacentini GL: Exhaled nitric oxide daily evaluation is effective in monitoring exposure to relevant allergens in asthmatic children. Chest $132: 1520-$ 1525, 2007

15) Hemmingsson T, Linnarsson D, Gambert $R$ : Novel hand-held device for exhaled nitric oxide-analysis in research and clinical applications. J Clin Monit Comput 18: 379-387, 2004

16) Kharitonov SA, Yates DH, Barnes PJ : Inhaled glucocorticoids decrease nitric oxide in exhaled air of asthmatic patients. Am J Respir Crit Care Med 153 : 454-457, 1996 
17) Sandrini A, Taylor DR, Thomas PS, Yates DH : Fractional exhaled nitric oxide in asthma : an update. Respirology $15: 57-70,2010$

18) Pijnenburg MW, Floor SE, Hop WC, De Jongste JC: Daily ambulatory exhaled nitric oxide measurements in asthma. Pediatr Allergy Immunol $17:$ 189-193, 2006

19) Menzies D, Nair A, Lipworth BJ : Portable exhaled nitric oxide measurement: Comparison with the "gold standard" technique. Chest $131:$ 410-414, 2007

20) Jatakanon A, Lim S, Kharitonov SA, Chung KF, Barnes PJ : Correlation between exhaled nitric oxide, sputum eosinophils, and methacholine responsiveness in patients with mild asthma. Thorax 53: 91-95, 1998

21) Lim S, Jatakanon A, Meah S, Oates T, Chung KF, Barnes PJ : Relationship between exhaled nitric oxide and mucosal eosinophilic inflammation in mild to moderately severe asthma. Thorax 55 : 184-188, 2000

22) van Rensen EL, Straathof KC, Veselic-Charvat MA, Zwinderman AH, Bel EH, Sterk PJ : Effect of inhaled steroids on airway hyperresponsiveness, sputum eosinophils, and exhaled nitric oxide levels in patients with asthma. Thorax 54 : 403-408, 1999

23) Gibson PG, Simpson JL, Saltos N : Heterogeneity of airway inflammation in persistent asthma: evidence of neutrophilic inflammation and increased sputum interleukin-8. Chest 119: 1329-1336, 2001

24) Jeffery PK : Remodeling and inflammation of bronchi in asthma and chronic obstructive pulmonary disease. Proc Am Thorac Soc 1: 176-183, 2004

25) Ichinose M, Sugiura H, Yamagata S, Koarai A, Shirato K : Increase in reactive nitrogen species production in chronic obstructive pulmonary disease airways. Am J Respir Crit Care Med 162 : 701-706, 2000

26) Stirling RG, Kharitonov SA, Campbell D, Robinson DS, Durham SR, Chung KF, Barnes PJ : Increase in exhaled nitric oxide levels in patients with difficult asthma and correlation with symptoms and disease severity despite treatment with oral and inhaled corticosteroids. Asthma and Allergy Group. Thorax 53 : 1030-1034, 1998

(2011. 3. 3 received; 2011. 5. 10 accepted) 